\title{
Maternal transmission of immunity to white spot syndrome associated virus (WSSV) in shrimp (Penaeus monodon)
}

\author{
Chih-Cheng Huang, Yen-Ling Song*
}

Department of Zoology, National Taiwan University, Taipei, Taiwan

Received 26 August 1998; received in revised form 12 January 1999; accepted 14 January 1999

\begin{abstract}
3-1,3-1,6-glucan, derived from bakers' yeast Saccharomyces cerevisiae, was used in the present study to investigate the extent to which glucan is able to protect spawners from white spot syndrome associated virus (WSSV), and whether this protection (if any) can be passed on to hatchlings via maternal transmission of immunity. Results showed that fewer spawners in the glucan-injected groups showed the clinical symptoms of red body coloration and white spots on the shell during the 15 days between eyestalk ablation and the end of repeated spawning. This suggests that the application of glucan might lead to a slight enhancement of disease resistance in spawners, although the differences were not statistically significant within the confidence limit chosen. Challenge results showed a significant increase in relative percent survival for larvae derived from groups of glucan-injected spawners compared to those derived from groups of untreated spawners. It therefore seems that a maternally transmitted disease resistance induced by glucan, protected the larvae against a WSSV infection. Glucan immersion was not only shown to be effective for nauplii derived from spawners that were not injected with glucan, it also provided additional, cumulative protection for nauplii which already had a maternally transmitted resistance to WSSV. This is the first documented demonstration of a maternal transmission of immunity in invertebrates. (C) 1999 Elsevier Science Ltd. All rights reserved.
\end{abstract}

Keywords: Maternal transmission; Immunity; White spot syndrome associated virus (WSSV); Shrimp

\section{Introduction}

The high mortality of spawners and hatchlings is a common problem in shrimp nurseries. The vulnerability of the spawners is increased by the

\footnotetext{
* Corresponding author. Tel.: + 886-2-23630231, Extn 3355; fax: + 886-2-23660243.

E-mail address: song@ccms.ntu.edu.tw (Y.-L. Song)
}

stress induced by eyestalk ablation, wound infection and/or brooding, all of which are believed to generally depress the animals' immune status and make them more susceptible to infection by baculovirus and Vibrio [1-5]. For hatchlings, on the other hand, the most critical periods seem to be the four metamorphic stages from nauplius, zoea and mysis to postlarvae. The transition from zoea to mysis is especially difficult and it is 
typically only survived by about $30-50 \%$ of the hatchlings. Various strategies against these high mortalities have been investigated. Thus, for example, since bacterial infections are often associated with the deaths of these hatchlings, Liu [6] investigated the efficiency of a sulfa drug (furazolidone) administered both orally and via an immersion route. In fact, the drug never reached bactericidal concentrations in the shrimp hemolymph [6], but in any case the problem with this approach is that drug residues not only induce drug-resistant strains but also result in environmental pollution. An alternative approach, in which an insoluble $\beta-1,3-1,6-$ linkaged glucan functions as an immunostimulant, has however, been demonstrated to enhance resistance to vibriosis and WSSV disease in shrimp [7,8]. The yeast glucan enhances disease resistance by activating the prophenoloxidase (proPO) system, releasing highly reactive oxygen species from hemocytes and inducing antimicrobial activity in plasma $[7,9,10]$.

Maternal transmission of immunity can occur in several different ways. In mice and chicken it is known to take place mainly via the egg sac [11-14] and a positive correlation has recently been found between the Ig level in the plasma of a mature female salmon and the Ig content in her eggs [15]. In Drosophila, embryonic patterning appears to be controlled by the binding of extracellular ligands that initiate and activate the Toll-Dorsal signaling pathway, but maternal effect genes in the signaling pathway have been found to be related to Drosophila's innate immune response at later developmental stages $[16,17]$. In the present study we investigate the extent to which glucan is able to protect spawners from white spot syndrome associated virus (WSSV), and whether this protection (if any) can be passed on to hatchlings via maternal transmission of immunity.

\section{Materials and methods}

Glucan suspension (supplied as an adjuvant ingredient by Biotech-Mackzymal AS, Norway) was processed as described in a previous report
[8] in preparation for both injecting spawners and bathing nauplii. Glucan was administered to spawners and nauplii during times when other cultural procedures already required the shrimp to be handled, so that the additional stress of multiple handling could be avoided.

In two separate trials, spawners of sufficient sexual maturity were selected based on body size $(10.5-11.5$ in. in body length) $[18,19]$ and reared in concrete ponds $(6 \mathrm{~mL} \times 4 \mathrm{~mW} \times 2 \mathrm{mH})$ containing re-circulated brackish water. Salinity was adjusted to $3.0 \%$ and the temperature was kept at $28^{\circ} \mathrm{C}$. One hundred $\mu \mathrm{l}$ shrimp sterile saline containing $100 \mu \mathrm{g}$ glucan was injected into the pericardial cavity of each experimental spawner using a 30 ga needle. Control spawners were similarly injected with saline alone. After being injected, spawners were disinfected in oxolinic acid solution for $3 \mathrm{~min}$ and then returned to the concrete ponds. The next day one eyestalk was ablated from each spawner to promote egg maturation. Spawners were fed with live feed 4-6 times per day until spawning at the fifth day. Diseased and dead spawners were counted during each of the 15 days from post ablation to the end of repeated spawning. The percentage of dead and diseased spawners in the glucaninjected and control groups were statistically analyzed with a $t$-test.

Eggs were produced either by natural crosses or by in vitro fertilization, and no attempt was made to distinguish between these two groups. Hatched nauplii were pooled 13-14 h postspawning, with nauplii derived from the glucaninjected spawners being kept separate from those derived from the spawner controls. Half of each group were then bathed in aerated brackish water containing glucan at $0.5 \mathrm{mg} / \mathrm{ml}$ (i.e. group $\mathrm{A}:+/+$ and group $\mathrm{C}:-/+)$. The other nauplii were bathed in the brackish water only (i.e. group B: $+/-$ and group $\mathrm{D}:-/-$; control group). Bath density was adjusted to 5.5 million nauplii per 500 liters of water in a round plastic container. The temperature was held at $32^{\circ} \mathrm{C}$. After immersion for $3 \mathrm{~h}$, each group of 5.5 million nauplii was transferred to separate indoor ponds which each contained 40 metric tons of brackish water. 
Table 1

Effects of $\beta$-1,3-1,6-glucan on the health status of Penaeus monodon spawners during their spawning period

\begin{tabular}{lllllr}
\hline Trial & $\begin{array}{l}\text { Number of } \\
\text { spawners }\end{array}$ & Glucan-injected & $\begin{array}{l}\text { Deaths after } \\
\text { injection }^{\mathrm{a}}\end{array}$ & $\begin{array}{l}\text { Deaths during } \\
\text { spawning }^{\mathrm{b}}\end{array}$ & $\begin{array}{l}\text { No. (\%) of survivors } \\
\text { with clinical symptoms }\end{array}$ \\
\hline I & 56 & + & 0 & 4 & $0 / 52(0)$ \\
II & 235 & - & 0 & 4 & $10 / 231(4)$ \\
& 49 & + & 1 & 2 & $1 / 46(2)$ \\
$7 / 37(19)$ \\
\hline
\end{tabular}

\footnotetext{
${ }^{\text {a }}$ Deaths occurring in the $24 \mathrm{~h}$ between injection and eyestalk ablation.

${ }^{\mathrm{b}}$ Deaths occurring during the 15 days of repeated spawning that followed eyestalk ablation. No significant difference was shown between injected and control spawners $(t$-test; $P=0.1982>0.05)$.

${ }^{\mathrm{c}}$ No significant difference was shown between injected and control spawners $(t$-test; $P=0.2996>0.05)$.
}

To determine whether glucan gave the larvae immunity to WSSV infection, 250 larvae were randomly taken from each of the four groups at the mysis and postlarva 0 stages (about 7 and 10 days post-hatching, respectively) and subjected to a challenge test. These viral infection experiments broadly followed the method of Momoyama and Sano [20] with modifications which have already been described in detail in a previous paper [8]. After exposure to WSSV by immersion, the larvae were returned to a beaker and maintained for another 5-6 days. They were fed with both artemia nauplii and artificial feed. Larvae were checked for viability every $4 \mathrm{~h}$ and bodies were removed immediately after death to keep the water clean. Because deaths that occurred within $24 \mathrm{~h}$ post-challenge probably resulted from mechanical injury or handling stress rather than infection, these 'non-infectious deaths' were subtracted from the calculations of larvae mortality. Larvae mortality (LM) was thus defined as follows:

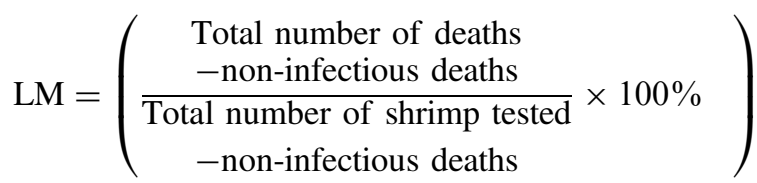

The challenge tests were terminated until two days had passed without an infectious death. The cumulative mortalities of larvae at the stationary phase were expressed in terms of relative percent survival (RPS):

$$
\begin{aligned}
& \text { RPS }=\left(1-\frac{\text { Mortality in experimental group }}{\text { Mortality in control group }}\right) \\
& \times 100 \%
\end{aligned}
$$

Differences between the paired groups (A and B, $\mathrm{B}$ and $\mathrm{D}, \mathrm{C}$ and $\mathrm{D})$ were examined using a Duncan's multiple range test of the cumulative mortalities of each group. Differences between the two sets of challenge groups (i.e. challenged at mysis vs challenged at PL0) were examined using a variance analysis (ANOVA) of the RPSs of each group. Differences between the four protocols (i.e. groups A, B, C and D) were also compared using Duncan's multiple range test.

\section{Results}

During the 15 days between ablation and the end of repeated spawning, spawner mortality was slightly higher in the glucan-injected groups than in the control groups (Table 1), although there were no statistical differences when the results were analyzed using a $t$-test. On the other hand, fewer spawners in the glucan-injected groups showed the clinical symptoms of red body coloration and white spots on the shell (Table 1), which suggests that application of glucan might lead to a slight enhancement of disease resistance in spawners, although again the differences were not statistically significant within the confidence limit chosen. 


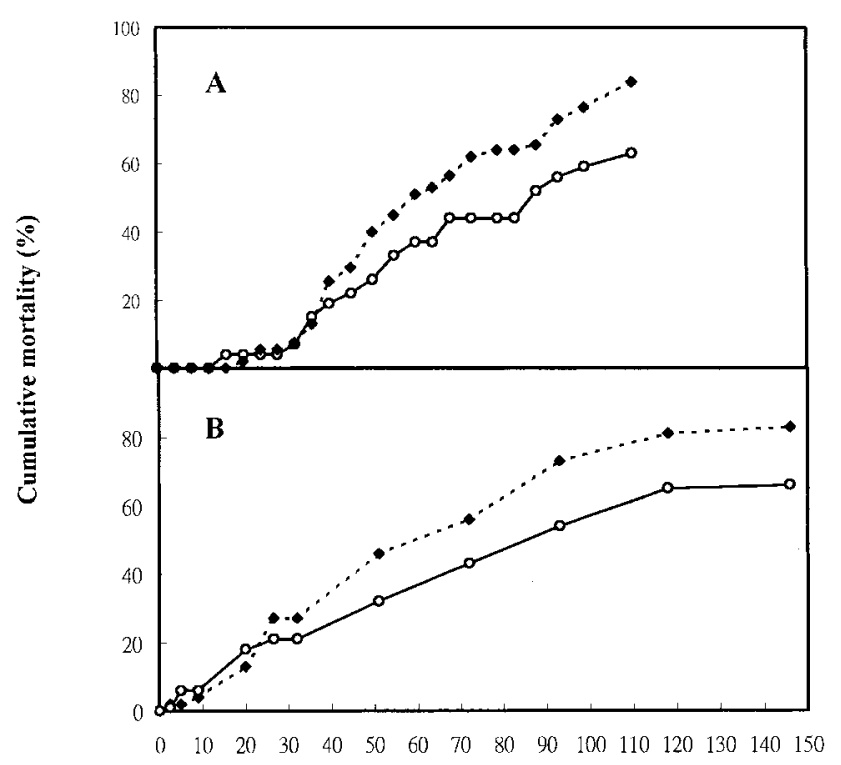

Hours post infection

Fig. 1. Cumulative mortality in WSSV-challenged offspring. (A) Offspring challenged at mysis (i.e. approx. 7 days after hatching). (B) Offspring challenged at PL0 (10 days posthatching). None of the nauplii shown here were immersed in the glucan suspension. $\cdots \bullet \cdots=$ larvae from untreated spawners $(-/-)$, group $\mathrm{D}) ;-\mathrm{O}-=$ larvae from glucan injected spawners $(+/-$, group B).

The cumulative mortalities for the offspring groups that were challenged at mysis (Fig. 1A)

Table 2

Relative percent survival (RPS) of larvae challenged by immersion in WSSV filtrates prepared from infected P. monodon

\begin{tabular}{llllll}
\hline & $\mathrm{A}$ & $\mathrm{B}$ & $\mathrm{C}$ & $\mathrm{D}$ \\
\hline Treatment $^{\mathrm{a}}$ & Spawners injected with glucan & + & + & - & - \\
& Nauplii immersed in glucan & + & - & + & - \\
RPS $(\%)^{\mathrm{b}}$ & Challenge at mysis stage $^{\mathrm{c}}$ & 68 & 25 & 27 & 0 \\
& Challenge at postlarva 0 stage $^{\mathrm{c}}$ & 51 & 21 & 20 & 0 \\
& Mean $^{\mathrm{d}}$ & $59.5^{\mathrm{A}}$ & $23^{\mathrm{B}}$ & $23.5^{\mathrm{B}}$ & $0^{\mathrm{C}}$ \\
\hline
\end{tabular}

${ }^{\text {a }}$ Symbol '+' represents glucan-treated and '-' non-treated.

${ }^{\mathrm{b}} \mathrm{RPS}=\left(1-\frac{\text { Mortality in exp. group }}{\text { Mortality in control group }}\right) \times 100 \%$.

${ }^{c}$ ANOVA showed no significant differences between these two challenges.

${ }^{\mathrm{d}}$ Duncan's multiple range test at a $5 \%$ confidence limit showed that the means differed significantly. Significantly different means are indicated by different letters. and PL0 (Fig. 1B) showed that more of the hatchlings derived from the glucan-injected spawners (i.e. group B) survived than those in the corresponding untreated spawner group (i.e. group D). Mortality rates were nevertheless quite similar, and Duncan's multiple range test showed that there was in fact no significant difference between any of the pairs of corresponding curves. However, because an ANOVA analysis of the RPS values also showed that there were no significant differences between the mysis and PLO challenge groups, the RPS results for these two groups can be combined. When mean RPS values are considered, the difference between groups $\mathrm{D}$ and B (23\%; see Table 2) is significant. This suggests that a maternally transmitted disease resistance induced by glucan has protected the larvae against a WSSV infection. A similar maternal transmission of immunity was also inferred from the differences between groups $\mathrm{C}$ $(23.5 \%)$ and A $(59.5 \%)$. Glucan immersion also increased survival rates, as shown by the $23.5 \%$ RPS increase between groups D and $\mathrm{C}$ and the $36.5 \%$ increase between groups B and A. Glucan immersion was thus shown to be effective for nauplii derived from spawners that were not injected with glucan, while it also provided additional, cumulative protection for nauplii which already had a maternally transmitted resistance to WSSV.

\section{Discussion}

During the 15 days between eyestalk ablation and the end of repeated spawning, the mortality of the spawners was slightly higher in the injected groups than in the control groups. However, there were fewer spawners showing clinical symptoms in the glucan-injected groups than in the corresponding controls. Even though neither of these differences were statistically significant, these data nonetheless suggest that induction of disease resistance by $100 \mu \mathrm{g}$ glucan does not occur immediately in spawners. At high concentrations, glucan has been reported to show no, or even adverse, effects in shrimp in terms of tissue damage and resistance to Vibrio infection [7]. 
Similarly, a high dose of levamisole suppresses the defense mechanisms of rainbow trout [21]. Robertsen et al. [22] and Jørgensen [23] also found that the onset timing of disease-resistance and/or stress-tolerance was glucan-dose dependent in salmonids, and suggested that while a low dose of immunostimulant (within an optimal range) will induce a quick-on and quick-off protection, a higher dose requires a lag period during which the glucan is metabolized, and protection is only initialized once the glucan concentration has fallen back to an optimal range. This in turn suggests that the injection dosage $(100 \mu \mathrm{g}$ glucan per spawner) used in the present study might have been too high. Nevertheless, inspiration comes from $\mathrm{Su}$ et al. who reported that Schizophyllum commune-derived $\beta$-1,3-glucan could enhance survival of $P$. monodon brooders during a 30-day feeding trial. They concluded that this daily oral dose $(0.2 \%$ glucan in the feed) stimulated hemocytes by significantly increasing phagocytic activity, cell adhesion and superoxide anion production [24].

Jarp and Tverdal [25] suggest that if the cumulative cases in immunostimulated and unimmunostimulated groups are registered at the end of the observation period, the immunostimulant effect can be measured with the risk ratio, risk difference or the RPS. RPS is the same as the preventive fraction or the immunostimulant effect [26,27]. RPS represents the fraction of the mortality that was prevented by the immunostimulant up to the end of the observation period, so RPS is dependent on the experimental conditions and the length of the observation period. A point estimate of RPS is very often used to present the results from fish vaccination trials, because a single value is clear, precise and easy to understand. Unfortunately, the very precision of this point estimate gives sometimes the misleading impression that the value presented is the correct answer [25].

In this study when the mysis and PL0 challenge groups are compared during the observation period, the difference in cumulative mortalities between any of the pairs of corresponding curves in group $\mathrm{B}$ and the control group (group D) are not statistically significant.
However, when the mysis and PL0 challenge data are compared at the end of the observation period, the difference between the mean RPSs does become significant. We have therefore demonstrated here that larvae derived from glucan-injected mothers had significantly higher survival rates than the control groups against an artificial infection with WSSV. To the best of our knowledge, this is the first documented demonstration of a maternal transmission of immunity in invertebrates.

Glucan immersion also improved survival rates. The $23.5 \%$ increase in RPS between groups $\mathrm{D}$ and $\mathrm{C}$ (Table 2) is similar to the $24-32 \%$ improvement in RPS previously reported for shrimp that were fed daily with $\beta$-glucan [8]. Furthermore, the larvae from glucan-injected mothers had even higher survival rates when they were restimulated at the nauplius stage $(59.5 \%$ RPS; see Table 2). In other words, stimulation of spawners and restimulation of the nauplii induced an additive protection effect in shrimp against WSSV infection.

Recently some studies on the proPO activating system (proPO-AS) in shrimp were carried out on the penaeid such as P. californiensis, P. japonicus, $P$. monodon, $P$. paulensis and as freshwater prawn (Macrobrachium rosenbergii). Phenoloxidase (PO) activity is found mainly in hemocytes $[7,28,29]$ and/or serum [30-32]. Enzyme activity was cation-dependent $[28,32,33]$. It can be enhanced by several microbial polysaccharides, including $\beta$-glucan from fungal cell walls $[7,10,28,32]$, laminarin from seaweed [31], lipopolysaccharides (LPS) from bacterial cell walls $[10,28,32]$. Additional factors found to activate the proPO system include SDS [31], trypsin $[28,32]$ and high temperature $[28,30]$. An immune factor, similar to the $76 \mathrm{kDa}$ protein from the crayfish, was found in the $P$. paulensis hemocytes, capable of inducing cell-adhesion and degranulation of the semigranulocytes and granulocytes [32]. A $\beta$-glucan-binding protein ( $\beta$ GBP) of $100 \mathrm{kDa}$ molecular mass, similar to the crayfish $\beta$ GBPs [34] in terms of amino acid composition in N-terminal sequence, has been identified in plasma of $P$. californiensis, capable of enhancing the proPO system activation induced by lami- 
narin [35]. In addition, a LPS-binding agglutinin [29] and a hemolytic factor [36] have been detected in brown shrimp ( $P$. californiensis) serum, although these proteins do not seem to be involved in proPO system stimulation. Although the proPO-AS is unraveled, the associated proteins of the penaeid shrimp are highly similar in terms of both structure and function to those observed in crustaceans [37]. We therefore believe that they may play an important role in shrimp defense mechanisms, too.

Although at this point we can only speculate upon the mechanisms that underlie the maternal transmission of immunity in shrimp, current evidence suggests that there might be several parallels between shrimp and Drosophila. Recently in kuruma shrimp ( $P$. japonicus) numerous microvilli were found on the surface of oocytes. Immunohistochemical staining showed that egg yolk protein may be transferred and incorporated into the ooplasma through these microvilli [38]. Söderhäll and Cerenius [37] have shown that the shrimp protein LP-1, which seems to be identical to the crayfish $\beta$ GBP, is involved in lipid transport to the ovary showing that reproduction and immunity might be linked in crustaceans. During the oogenesis Drosophila maternal RNA and proteins are transported from follicle cells into the oocytes and affect embryo development [39]. In Drosophila, embryonic patterning appears to be controled by the binding of extracellular ligands that initiate and activate the Toll-Dorsol signaling pathway, but maternal effect genes in the signaling pathway have been found to be related to Drosophila's innate immune response at later development stages [16,17]. It is tempting to speculate that there may also be a link between the proPO-AS and the induction of antimicrobial syntheses in shrimp, since a $\beta$ GBP has been identified in brown shrimp P. californiensis [35] and a serine proteinase associated with the proPO-AS is likely to induce activation of the Toll-signaling pathway in Drosophila, leading to synthesis of antimicrobial peptides [37]. Besides, structural similarities in C-terminal portions between coagulogen from coagulation cascade of horseshoe crab and spatzle, the ligand of the Toll receptor involving in Drosophila Toll-signaling pathway, and proposed similarity between at least two of their processing serine proteinase in each cascade (factor B, proclotting enzyme versus Snake and Easter) have been detected [40]. By analogy with the Drosophila Toll-signaling pathway, we hypothesize that a prospatzle-like protein may be present in shrimp hemolymph or hemocyte and that it is processed by a proteinase which may be involved in the proPO-AS or coagulation cascade and activated by $\beta$-glucan. The spatzle-like molecules may act as ligands to induce activation of the Toll-signaling pathway, leading to synthesis of maternal mRNA or antimicrobial peptides that transfer into the ooplasm through the microvilli and enhance disease resistance of larvae at later developmental stages. This interesting possibility will need to be investigated in future studies.

\section{Acknowledgements}

We thank Biotech-Mackzymal AS Company (Tromso, Norway) for kindly providing $\beta$-glucan for this experiment. We thank Professor YingChou Lee, Institute of Fishery Science, National Taiwan University for the statistical analysis. Sincere thanks are also extended to Professor Masaaki Ashida, the Institute of Low Temperature Science, Hokkaido University for the many valuable points he raised during discussions. This research was financially sponsored by the Council of Agriculture, under Grants No. 85AD-6.3-F-11(6-10) and 87BT-2.1-FID-01(5-1).

\section{References}

[1] Lightner DV. A review of the diseases of cultured Penaeid shrimps and prawns with emphasis on recent discoveries and developments. In: Proceedings of the First International Conference on the Culture of Penaeid Prawns/Shrimps. Iloilo City, Philippines, 1984. p. 79103.

[2] Chantanachookin C, Boonyaratpalin S, Kasornchandra J, Direkbusarakom S, Ekpanithanpong U, Supamataya K, Sriurairatana S, Flegel TW. Histology and ultrastructure reveal a new granulosis-like virus in Penaeus monodon affected by yellow-head disease. Diseases of Aquatic Organisms 1993;17:145-57. 
[3] Song YL, Cheng W, Wang CH. Isolation and characterization of Vibrio damsela infectious for cultured shrimp in Taiwan. Journal of Invertebrate Pathology 1993;61:24-31.

[4] Lightner DV, Redman RM, Hasson KW, Pantoja CR. Diseases of Aquatic Organisms. Taura syndrome in Penaeus vannamei: histopathology and ultrastructure 1995;21:53-9.

[5] Lo CF, Leu JH, Ho CH, Chen CH, Peng SE, Chen YT, Chou CM, Yeh PY, Huang CJ, Chou HY, Wang CH, Kou GH. Detection of baculovirus associated with white spot syndrome (WSBV) in penaeid shrimps using polymerase chain reaction. Diseases of Aquatic Organisms 1996;25:133-41.

[6] Liu CK. Distribution and residue of furazolidone in prawns. Fish Disease Research 1992;12:20-6.

[7] Sung HH, Kou GH, Song YL. Vibriosis resistance induced by glucan treatment in tiger shrimp (Penaeus monodon). Fish Pathology 1994;29:11-7.

[8] Song YL, Liu JJ, Chan LC, Sung HH. Glucan-induced disease resistance in tiger shrimp (Penaeus monodon). In Gudding R, Lillehaug A, Midtlyng PJ, Brown F, editors. Fish vaccinology. Developments in biological standardization. Basel: Karger, 1997;90:335-43.

[9] Song YL, Hsieh YT. Immunostimulation of tiger shrimp (Penaeus monodon) hemocytes for the generation of microbicidal substances - An analysis of the reactive oxygen species. Developmental and Comparative Immunology 1994;18:201-9.

[10] Sung HH, Yang YL, Song YL. Enhancement of microbicidal activity in tiger shrimp (Penaeus monodon) via immunostimulation. Journal of Crustacean Biology 1996;16:279-85.

[11] Morshed MG, Yokota M, Nakazawa T, Kinishi H. Transfer of antibody against Borrelia duttonii from mother to young in ddY mice. Infection and Immunity 1993;61:4147-52.

[12] Smith NC, Wallach M, Miller CMD, Morgenstern R, Braun R, Eckert J. Maternal transmission of immunity to Eimeria maxima: enzyme-linked immunosorbent assay analysis of protective antibodies induced by infection. Infection and Immunity 1994;62:1348-57.

[13] Smith NC, Wallach M, Petracca M, Braun R, Eckert J. Maternal transfer of antibodies induced by infection with Eimeria maxima partially protects chickens against challenge with Eimeria tenella. Parasitology 1994;190:551-7.

[14] Hassan JO, Curtiss III R. Effect of vaccination of hens with an avirulent strain of Salmonella typhimurium on immunity of progeny challenged with wild-type Salmonella strain. Infection and Immunity 1996;64:93844.

[15] Olsen YA, Press CM. Degradation kinetics of immunoglobulin in the egg, alevin and fry of Atlantic salmon, Salmo salar L., and the localization of immunoglobulin in the egg. Fish and Shellfish Immunology 1997;7:81-91.

[16] Ip YT, Levine M. Molecular genetics of Drosophila immunity. Current Opinion in Genetic Development 1994;4:672-7.

[17] Hoffmann JA. Innate immunity of insects. Current Opinion in Immunology 1995;7:4-10.

[18] Cheng F, Reid B, Arnold CR. Maturing, spawning and egg collecting of the white shrimp Penaeus vannamei Boone in a recirculating system. Journal of the World Aquaculture Society 1991;22:167-72.

[19] Cavalli RO, Scardua MP, Wasielesky WJr. Reproductive performance of different sized wild and pond-reared Penaeus paulensis females. Journal of the World Aquaculture Society 1997;28:260-7.

[20] Momoyama K, Sano T. A method of experimental infection of kuruma shrimp larvae, Penaeus japonica Bate, with baculovirus mid-gut gland necrosis (BMN) virus. Journal of Fish Diseases 1988;11:105-11.

[21] Anderson DP, Siwicki AK, Dixon OW, Lizzio EF. Immunostimulation by levamisole in rainbow trout (Salmo gairdneri) in vivo. In: Ahne W, Kurstak E, editors. Viruses of lower vertebrates. New York: Springer, 1989. p. 469-78.

[22] Robertsen B, Rørstad G, Engstad R, Raa J. Enhancement of non-specific disease resistance in Atlantic salmon, Salmo salar L., by a glucan from Saccharomyces cerevisiae cell walls. Journal of Fish Diseases 1990;13:391-400

[23] Jørgensen JB. Stimulation of antibacterial mechanisms in salmonid macrophages by yeast $\beta$-glucan and bacterial lipopolysaccharide. $\mathrm{PhD}$ thesis, the Norwegian College of Fishery Science, University of Tromsø, Norway, 1994.

[24] Su MS, Chang CF, Yang CH, Liao IC. Viability enhancement of Penaeus monodon brooders by $\beta$-1,3-glucan derived from Schizophyllum commune. Annual report of National Science Council project, 1998. 11.

[25] Jarp J, Tverdal A. Statistical aspect of fish vaccination trials. In: Gudding R, Lillehaug A, Midtlyng PJ, Brown $\mathrm{F}$, editors. Fish vaccinology. Developments in biological standardization. Basel: Karger, 1997;90:311-20.

[26] Miettinen OS. Proportion of disease caused or prevented by a given exposure, trait or prevention. American J Epidemiology 1974;99:325-32.

[27] Amend DF. Potency testing of fish vaccines. In: Anderson DP, Hennessen W, editors. Fish biologics: serodiagnostics and vaccines. Developments in biological standardization. Basel: Karger, 1981;49:447-54.

[28] Sung HH, Chang HJ, Her CH, Chang JC, Song YL. Phenoloxidase activity of hemocytes derived from Penaeus monodon and Macrobrachium rosenbergii. Journal of Invertebrate Pathology 1998;71:26-33.

[29] Vargas-Albores F, Guzmán-Murillo A, Ochoa JL. A Lipopolysaccharide-binding agglutinin isolated from brown shrimp (Penaeus californiensis Holmes) haemolymph. Comparative Biochemistry and Physiology 1993;104:407-13.

[30] Kondo M, Itami T, Takahashi Y. The phenoloxidase activity in prawn hemocytes. Gyobyo Kenkyu 1992;27:185- 
[31] Hernandez-Lopez J, Gollas-Galvan T, Vargas-Albores F Activation of the prophenoloxidase system of the brown shrimp (Penaeus californiensis Holmes). Comparative Biochemistry and Physiology 1996;113C:61-6.

[32] Perazzolo LM, Barracco MA. The prophenoloxidase activating system of the shrimp Penaeus paulensis and associated factors. Developmental and Comparative Immunology 1997;21:385-95.

[33] Gallas-Galvan T, Hernandez-Lopez J, Vargas-Albores F. Effect of calcium on the prophenoloxidase system activation of the brown shrimp (Penaeus californiensis Holmes). Comparative Biochemistry and Physiology 1997;117A:419-25.

[34] Duvic B, Söderhäll K. $\beta$-1,3-glucan-binding proteins from plasma of the fresh-water crayfishes Astacus astacus and Procambarus clarkii. Journal of Crustacean Biology 1993;13:403-8.

[35] Vargas-Albores F, Jiménez-Vega F, Söderhäll K. A plasma protein isolated from brown shrimp (Penaeus californiensis) which enhances the activation of prophe- noloxidase system by $\beta$-1,3-glucan. Developmental and Comparative Immunology 1996;20:299-306.

[36] Guzman M, Ochoa JL, Vargas-Albores F. Hemolytic activity in the brown shrimp (Penaeus califoniensis Holmes) Hemolymph. Comparative Biochemistry and Physiology 1993;106A:271-5.

[37] Söderhäll K, Cerenius L. Role of the prophenoloxidaseactivating system in invertebrate immunity. Current Opinion in Immunology 1998;10:23-8.

[38] Yano I, Krol RM, Overstreet RM, Hawkins WE. Route of egg yolk protein uptake in the oocytes of kuruma prawn, Penaeus japonicus. Marine Biology 1996;125:77381.

[39] Anderson KV, Nüsslein-Volhard C. Information for the dorsal-ventral pattern of the Drosophila embryo is stored as maternal mRNA. Nature 1984;331:223-7.

[40] Bergner A, Oganessyan V, Muta T, Iwanaga S, Typke D, Huber R, Bode W. Crystal structure of coagulogen, the clotting protein from horseshoe crab: a structural homologue of nerve growth factor. The EMBO Journal 1996;15:6789-97. 